\title{
Research on Process of Multi-point Micro Laser Shock Forming
}

\author{
Yujie FAN ${ }^{1,2, a}$, Erbin $\mathrm{GUO}^{2, \mathrm{~b}}$, Jianzhong $\mathrm{ZHOU}^{1, \mathrm{c}}$, Kaiting YIN ${ }^{2, \mathrm{~d}}$, \\ Pengfei $\mathrm{CUI}^{2, \mathrm{e}}$ \\ ${ }^{1}$ School of Mechanical Engineering, Jiangsu University, Zhenjiang 212013, China \\ ${ }^{2}$ School of Mechanical Engineering, Jiangsu University of Science and Technology, Zhenjiang \\ 212000, China \\ afanyujie1979@163.com, b1124722629@qq.com, 'zhoujz@ujs.edu.cn, d897249624@qq.com, \\ e1395846408@qq.com
}

\begin{abstract}
Keywords: Micro laser shock forming; Impact deformation; Copper;
Abstract:In order to study deformation feature of multi-point micro laser shock forming and distribution of impact surface morphology, single pass with multi-point forming experiments on copper T2 were conducted with Spitlight Nd: YAG laser ; Typical paths were introduced to characterize forming shape and distribution of impact surface morphology; Influence law of process parameters on micro laser shock forming was discussed. The results show that laser energy, overlapping rate and laser spot diameter are the main influence factors on impact deformation and surface morphology; Deformation and surface roughness increase with increment of laser energy. With the increase of the laser energy, the maximal deformation of metal sheet increases from 344.6 $\mu \mathrm{m}$ to $527.3 \mu \mathrm{m}$, and the surface waviness of the Path1, path2 and path3 were increased by $38.8 \%, 47.37 \%$ and $75.41 \%$. When the overlapping rate increases from $0 \%$ to $50 \%$, the maximal deformation of metal sheet increases from $344.6 \mu \mathrm{m}$ to564.6 $\mu \mathrm{m}$, and the waviness on the path of path1,path 2 and path 3 are reduced by $9.46 \% 、 6.37 \% 、 9.81 \%$. The higher the lapping rate is, the better the surface smoothness is. When the light spot diameter increases from $1 \mathrm{~mm}$ to $1.8 \mathrm{~mm}$, the deformation of metal sheet gradually becomes smaller, and the waviness on the path of path1,path2 and path 3 are reduced by $44.22 \%, 47.03 \% 、 55.1 \%$. The larger the light spot diameter is, the better the surface smoothness is. It provides good guidance for the selection of process parameters in micro laser shock forming and surface quality control by the analysis and reasonable characterization.
\end{abstract}

\section{Introduction}

With rapid development of Micro-Electromechanical System, micro parts are more and more widely used in scientific research and production. Micro parts mainly used in aeronautical, precision instrument and so on due to low energy consumption and portable light. Micro parts can be made by traditional blanking, forging, molding, or micro extrusion, slightly curved, micro shock forming and other new technologies[1]. Traditional micro machining is unable to meet the requirements of more complex parts in die design, installation, manufacturing, etc.[2]. Micro laser shock forming is a new flexible, clean and precision forming technique in recent years, which provides a new method for the study of plastic forming process of metal sheet. As a flexible processing method, micro laser shock forming integrates the technologies of laser shock peening (LSP) and high efficient plastic forming processing, with the following advantages[3]: (1) Ultrahigh pressure; (2) Extremely fast process: pulse width only ns; (3) High flexible: laser energy, impact path and diameter of laser spot can be well controlled; (4) Applicability for wide range of materials; (5) High surface quality: beneficial residual compressive stress is induced on the surface of material, which can improve surface corrosion resistance and fatigue life. High amplitude shock wave induced by laser has been widely applied to 
improve material surface hardness, wear resistance, and fatigue lives researched by domestic and foreign scholars $[4,6]$. At present, micro laser shock forming technology has been used to drawing and bulging aluminum foil, copper foil and low carbon steel experiments. The results show that mechanical properties of sheet were improved greatly and grain size was refined[7,9]. Furthermore, multi-point laser shock forming is needed for complex shape with the result of accumulating small dent to large deformation. Micro laser shock forming has greater influence on surface morphology due to diameter of laser spot and the shock distance at the same order of magnitude. It is important to control surface morphology of laser shock forming besides shape forming[10].

Copper has excellent properties such as thermal conductivity, ductility and corrosion resistance. T2 copper is the most commonly used in micro metal components due to superior electrical and mechanical properties. T2 copper was adopted in micro laser shock forming experiment; Typical paths were selected to characterize forming features and impacted surface morphology. In order to study the influence law of process parameters on micro laser shock forming, laser energy, overlapping rate and diameter of laser spot were selected as variables. By the research on process of multi-point micro laser shock forming, good guidance for selection of process parameters is provided in micro laser shock forming and surface quality control.

\section{Principle of micro laser shock forming}

Fig. 1[11] shows the principle of micro laser shock forming. High intensity and short pulse laser beams 1 acts on absorbing layer 3 permeated through confining layer 2 .Absorbing layer vaporizes and forms plasma by laser irradiation. High pressure and short duration shock wave generates and propagates into the metal material as the plasma continuing absorption of laser energy. Plastic deformation will be developed at subsurface and surface due to the peak pressure of the shock wave exceeding dynamic yield strength. Before laser shock experiment, copper T2 with black paint deposited on surface is placed on micro die. Black paint protects target from thermal damage served as energy absorption layer. K9-glass was selected as confining layer, which increases the intensity of the pulse pressure of shock wave ${ }^{[8]}$.

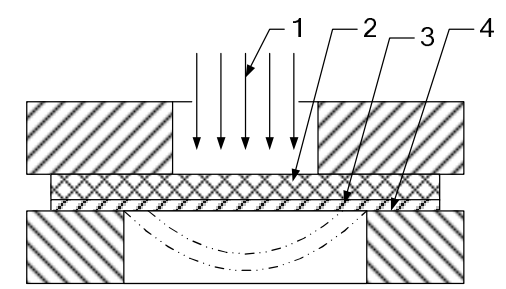

1. Laser, 2.Confining layer, 3.Absorbing layer, 4.Metal sheet

Fig. 1[11] Schematic of laser shock forming of sheet metal

\section{Characterization of single pass with multi-point forming}

In order to study the change law of deformation and surface morphology after multi-point laser shock processing, path 1, path 2 and path 3 were selected in X direction as shown in Fig. 2 (a), path1 is across center of laser spot, path 2 is $0.6 \mathrm{R}$ offset center of laser spot and path3 is R offset center of laser spot. Path 4, path 5 and path6 were selected in Y direction as shown in Fig. 2(b), path 4 is across center of laser spot, path 5 is $0.5 \mathrm{R}$ offset center of laser spot and path6 is $\mathrm{R}$ offset center of laser spot.

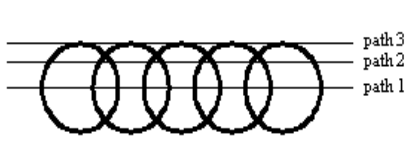

(a) $\mathrm{X}$ direction

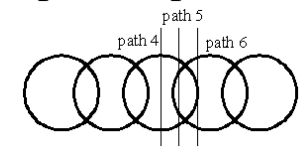

(b) Y direction

Fig. 2 Typical paths in $\mathrm{X}$ and $\mathrm{Y}$ direction 


\section{Experiments}

Micro laser shock forming experiment.Micro laser shock forming experiment was conducted using Spitlight Nd: YAG laser, with wave length $1064 \mathrm{~nm}$ and FWHM (Full Width at Half Maximum) of the pulses about $8 \mathrm{~ns}$. Micro dies were designed to explore the influence of different boundary conditions and path trajectories on plastic deformation. Fig.3 (a) shows the micro dies made of 45 -steel with size of the single channel $1 \times 10 \mathrm{~mm}, 1.4 \times 10 \mathrm{~mm}$ and $1.8 \times 10 \mathrm{~mm}$, respectively. The hole was machined by wire-electrode cutting. Figure 3 (b) shows a portable fixture which the workpiece was clamped on manually.
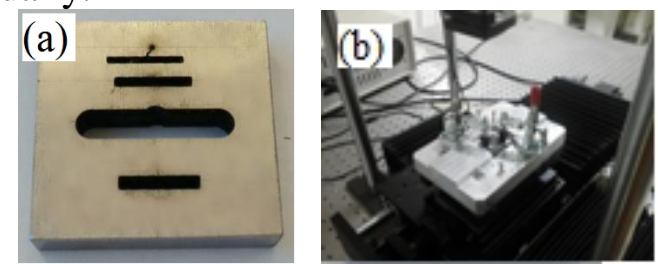

Fig.3 (a) Micro die and (b)fixture

The material of sheet metal in the paper was T2 copper with $0.05 \mathrm{~mm}$ thickness. Performance parameters of $\mathrm{T} 2$ copper are listed in Table 1 . In order to investigate the influence of process parameters on deformation and surface morphology, multi-point laser shock forming experiments were conducted with laser

energy $0.4 \mathrm{~J}, 0.6 \mathrm{~J}$ and $0.8 \mathrm{~J}$, overlapping rate $0,30 \%$ and $50 \%$, and laser spot diameter $1 \mathrm{~mm}, 1.4 \mathrm{~mm}$ and $1.8 \mathrm{~mm}$.

The trajectories of laser shock forming were shown in Fig. 4.

Tab. 1 The performance parameters of $\mathrm{T} 2$

\begin{tabular}{ccccccc}
\hline Mechanical & $\sigma_{b}(\mathrm{MPa})$ & $\sigma_{0.2}(\mathrm{MPa})$ & $E(\mathrm{GPa})$ & $\rho\left(\mathrm{kg} / \mathrm{m}^{3}\right)$ & $v$ \\
\hline Prpperties & 185 & 144 & 108 & 8930 & 0.32 \\
\hline
\end{tabular}

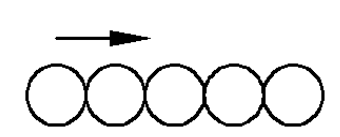

(a) $\eta=0$

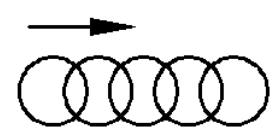

(b) $\eta=30 \%$

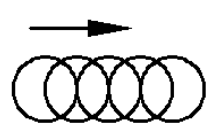

(c) $\eta=50 \%$

Fig.4 Different overlapping rate

3-D profile measurement.VHX1000C was used to measure 3-D surface profile. It is especially suitable for the specimen with circular arc transition plane to measure deformation of depth and width.

Surface roughness measurement.Axio CSM 700 true color microscopy was used to observe the surface morphology and roughness of the impacted region. Maximum observation area of single image is $1.5 \mathrm{~mm} \times 1.5 \mathrm{~mm}$. The configuration of the automatic scanning platform is to obtain the 3D profile, and 3D reconstruction can be conducted.

\section{Results and discussion}

Single pass with multi-point laser shock forming.Single pass with multi-point laser shock forming is each micro dent induced by laser shock with a certain overlapping rate. Deformation of the plate surface affected by the adjacent area forms certain contour shape. Figure 5 shows a typical surface morphology induced by single pass with multi-point laser shock forming, with laser energy 
$0.2 \mathrm{~J}$, spot diameter $1 \mathrm{~mm}$, overlapping rate $30 \%$ and size of the die $1 \mathrm{~mm} \times 10 \mathrm{~mm}$. Fig. 6 (a), (b) shows forming profile of single pass with multi-point laser shock in both $\mathrm{X}$ and $\mathrm{Y}$ direction. It shows that plastic deformation is induced in shock region. The largest plastic deformation is along path 1. Meanwhile, the surface properties and quality are improved. Improvement of the surface quality is more obvious when sheet surface is rougher.

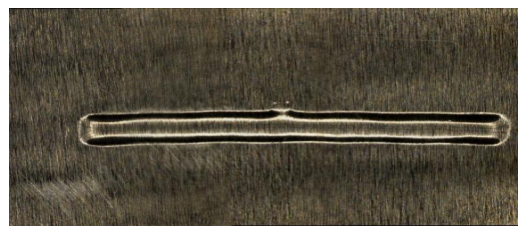

Fig.5 Surface morphology after single path laser shock

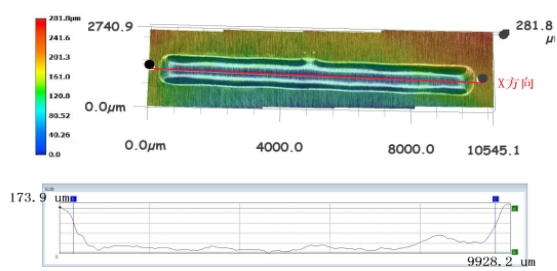

(a) X direction

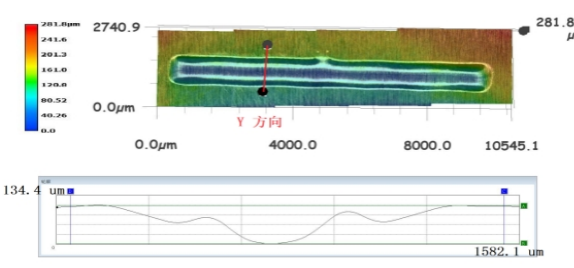

(b) Y direction

Fig.6 Forming profile of single path with multi-point laser shock

Fig. 7 shows deformation of multi-point laser shock along different paths. It can be observed that the plastic deformation across path1, path2 and path3 is homogeneous and with undulating shape in X direction. From center to edge of laser spot, plastic deformation decreases gradually. The maximum deformation value was $151.8 \mathrm{um}, 141.6 \mathrm{um}$ and $120.1 \mathrm{um}$, respectively. Meanwhile, longitudinal deformation decreases with increasement of the distance to the spot center.

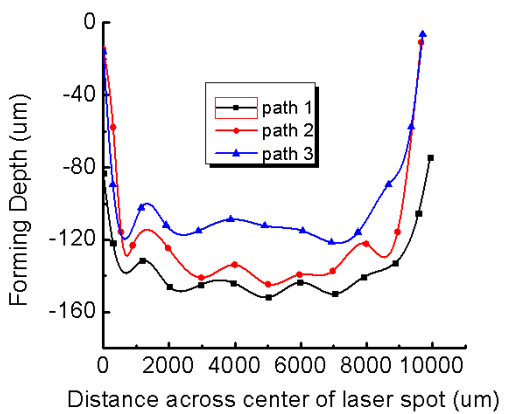

(a) $\mathrm{X}$ direction

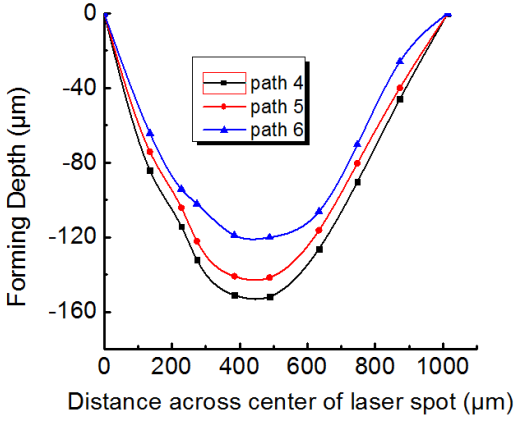

(b) Y direction

Fig.7 Deformation of different paths induced by multi-point micro laser shock

\section{Effect of process parameters on micro laser shock forming}

Overlapping rate. Fig. 8 shows contour curves of impact deformation along characteristics path. T2 copper is $0.05 \mathrm{~mm}$ in thickness, size of die $1 \mathrm{~mm} \times 10 \mathrm{~mm}$, with energy $0.6 \mathrm{~J}$, spot diameter $1 \mathrm{~mm}$ and overlapping rate $0,30 \%, 50 \%$, respectively. It can be observed that the deformation was even more obviously with increase of overlapping rate while surface waviness decreased obviously. When the overlapping rate increases from $0 \%$ to $50 \%$, the maximal deformation of metal sheet increases from $344.6 \mu \mathrm{m}$ to $564.6 \mu \mathrm{m}$, and the waviness on the path of path1,path2 and path3 are reduced by $9.46 \% 、 6.37 \%, 9.81 \%$. The higher the overlapping rate is, the better the surface smoothness is. This is resulted by the interaction of single point plastic deformation. Shock number is different in the region of each path since lase spot is circular and overlapping rate are different, Thus, distribution of surface morphology was different for different overlapping rate. Table 2 shows maximum forming depth of T2 copper under different overlapping rate. The curves of change of surface waviness with 
different overlapping rate are shown in Fig. 9. It can be seen that the shock forming surface becomes smooth and flat with increasing overlapping rate. However, productivity will reduce with increase of overlapping rate. Therefore, proper overlapping rate is very important in the process of micro laser shock forming.

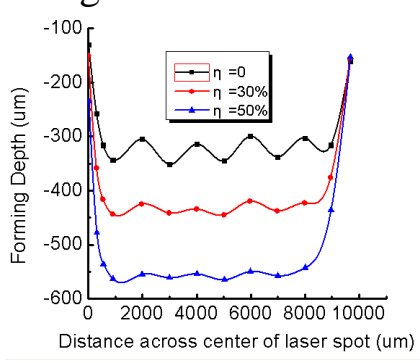

path1

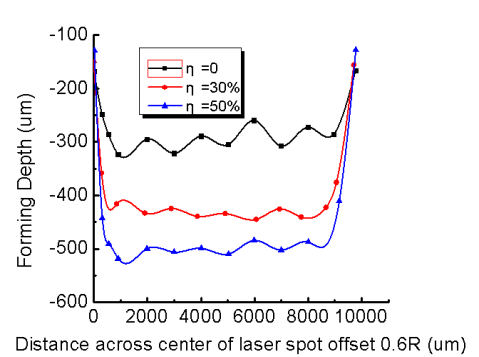

path2

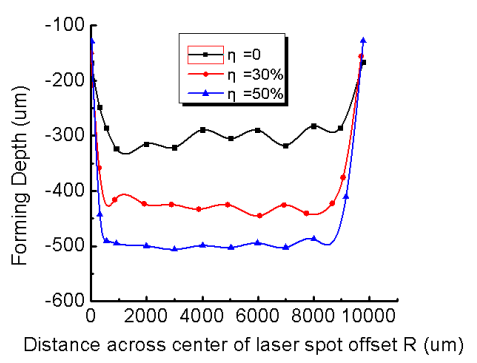

path3

Fig.8 Deformation curve across different paths

Tab.2 Maximum deformation under different overlapping rate (um)

\begin{tabular}{cccc}
\hline$\eta$ & 0 & $30 \%$ & $50 \%$ \\
\hline Path 1 & 344.6 & 439.7 & 564.6 \\
Path 2 & 323.1 & 438.5 & 518.1 \\
Path 3 & 317.3 & 434.6 & 502.6 \\
\hline
\end{tabular}

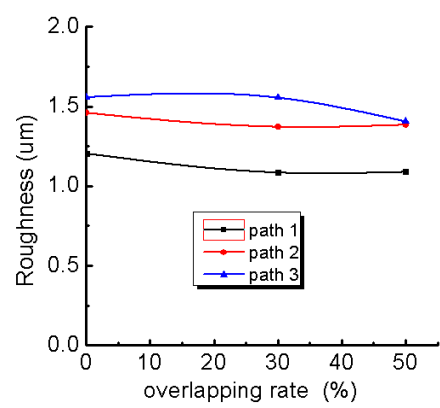

Fig. 9 Surface waviness under different overlapping rate

Laser energy. Fig.10 shows contour curves of impact deformation across characteristics path under different laser energies $0.4 \mathrm{~J}, 0.6 \mathrm{~J}$ and $0.8 \mathrm{~J}$, with overlapping rate $30 \%$, size of die $1 \mathrm{~mm} \times 10$ $\mathrm{mm}$, spot diameter $1 \mathrm{~mm}$.

It can be seen that the deformation across each path are cycle distribution, and the maximum surface deformation and waviness both increase obviously with increasement of laser energy. The maximum deformation of T2 copper under different energy is shown in table 3 . The change curves of surface waviness with laser energy are shown in Fig.11. It can be seen that the surface waviness increase with increasement of laser energy. When the laser energy increase from $0.4 \mathrm{~J}$ to $0.8 \mathrm{~J}$, the maximal deformation of metal sheet increases from $344.6 \mu \mathrm{m}$ to $527.3 \mu \mathrm{m}$, and the surface waviness of the Path 1, path 2 and path 3 were increased by $38.8 \%, 47.37 \%$ and $75.41 \%$. This is because the higher laser energy, the stronger the impulse wave induced by laser, and the greater the plastic deformation. When the overlapping rate remains constant, the surface waviness is clearer with the more powerful laser energy and the stronger impulse wave. 

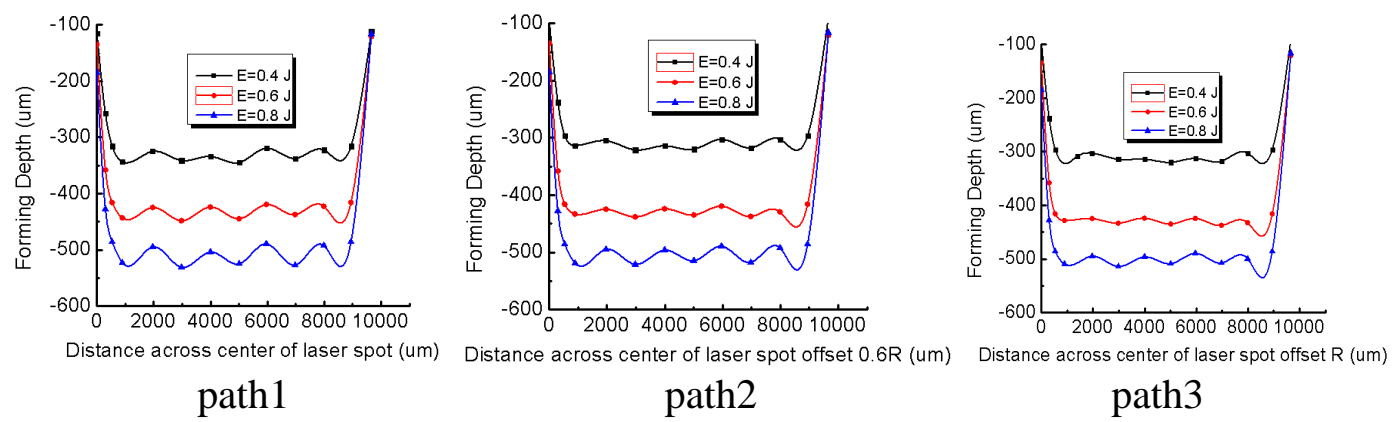

Fig. 10 Deformation curve across different paths

Tab.3 The maximum deformation under different energy (um)

\begin{tabular}{cccc}
\hline E & $0.4 \mathrm{~J}$ & $0.6 \mathrm{~J}$ & $0.8 \mathrm{~J}$ \\
\hline Path 1 & 344.6 & 444.6 & 527.3 \\
Path 2 & 319.6 & 437.3 & 519.1 \\
Path 3 & 318.4 & 437.2 & 508.6 \\
\hline
\end{tabular}

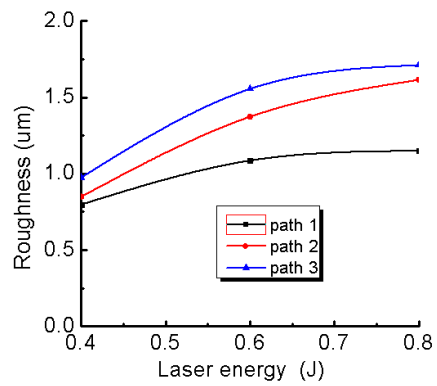

Fig.11 Surface roughness under different energy

Diameter of laser spot. Fig. 12 shows deformation curve with spot diameter of $1 \mathrm{~mm}, 1.4 \mathrm{~mm}$, $1.8 \mathrm{~mm}$, respectively, with size of the die $1.8 \mathrm{~mm} \times 10 \mathrm{~mm}$, overlapping rate 0 , laser energy $0.4 \mathrm{~J}$. The maximum deformation of T2 copper under different diameters of laser spot ARE shown in Table 4. It can be seen that surface smoothness increases with increment of laser spot diameter. While, impact deformation decreases. This is because laser beam power density decreases when laser spot diameter increases under the same laser energy, the pressure of impulse shock wave decreases.

Fig.13 shows the change of surface waviness under different diameter of laser spot. When the diameter of laser spot increases from $1 \mathrm{~mm}$ to $1.8 \mathrm{~mm}$, the deformation of metal sheet gradually becomes smaller , and the waviness on the path of path1,path2 and path 3 are reduced by $44.22 \%$ 、 $47.03 \% 、 55.1 \%$.The larger the light spot diameter is, the better the surface smoothness is. It is the result that single point plastic deformation decreases with increasement of diameter of laser spot. In addition, overlapping rate increases while diameter of laser spot increases.
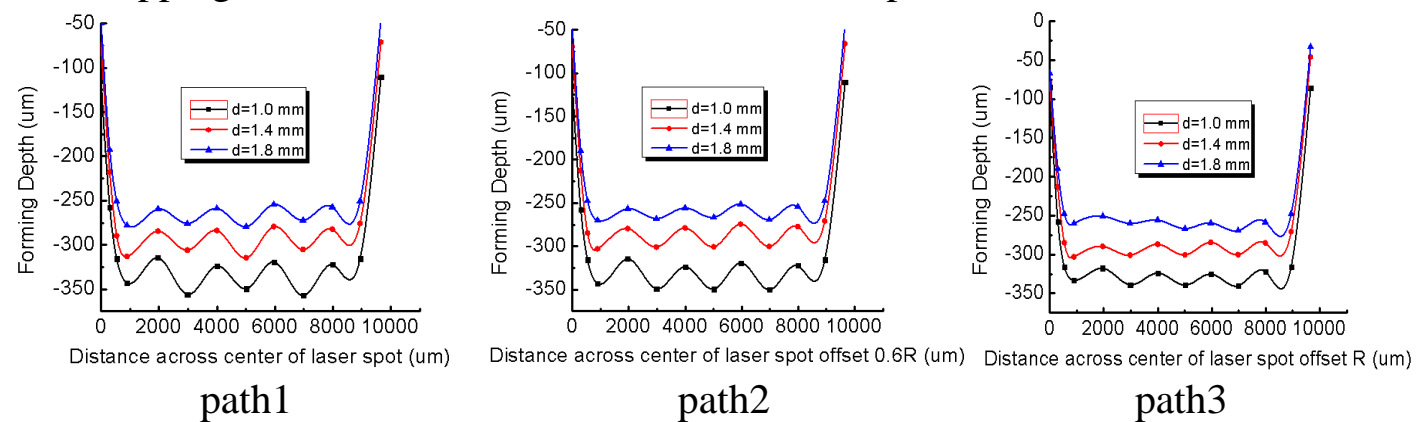

Fig.12 Surface roughness under different diameter of laser spot 
Tab.4 Maximum deformation under different diameter of laser spot (um)

\begin{tabular}{cccc}
\hline $\mathrm{d}$ & $1.0 \mathrm{~mm}$ & $1.4 \mathrm{~mm}$ & $1.8 \mathrm{~mm}$ \\
\hline Path 1 & 357.3 & 314.6 & 279.6 \\
Path 2 & 350.3 & 303.1 & 270.1 \\
Path 3 & 340.4 & 302.9 & 269.3 \\
\hline
\end{tabular}

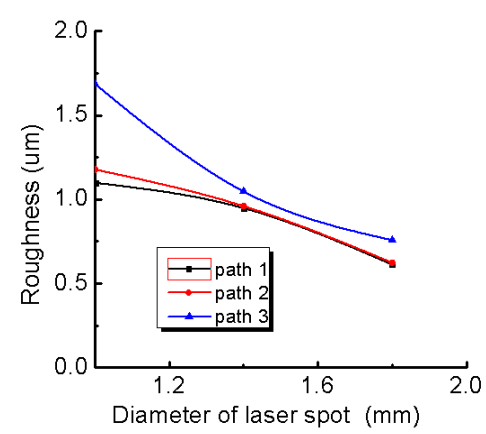

Fig.13 Surface roughness under different diameter of laser spot (um)

\section{Conclusions}

Plastic deformation was obtained by single pass with multi-point micro laser shock forming experiment. Typical paths were introduced to characterize forming shape and deformation distribution of impact region reasonably. Influence laws of process parameters on micro laser shock forming and surface morphology were discussed, and conclusions were drawn as: Multi-point micro laser shock forming is the accumulation of single point micro laser shock forming, which is influenced by laser energy, laser spot diameter and overlapping rate; With the increase of the laser energy, the maximal deformation of metal sheet increases from $344.6 \mu \mathrm{m}$ to $527.3 \mu \mathrm{m}$, and the surface waviness of the Path 1, path 2 and path 3 were increased by $38.8 \%, 47.37 \%$ and $75.41 \%$. When the overlapping rate increases from $0 \%$ to $50 \%$, the maximal deformation of metal sheet increases from $344.6 \mu \mathrm{m}$ to $564.6 \mu \mathrm{m}$, and the waviness on the path of path1, path2 and path3 are reduced by $9.46 \% 、 6.37 \% 、 9.81 \%$. The higher the lapping rate is, the better the surface smoothness is. When the diameter of laser spot increases from $1 \mathrm{~mm}$ to $1.8 \mathrm{~mm}$, the deformation of metal sheet gradually becomes smaller, and the waviness on the path of path 1, path 2 and path 3 are reduced by $44.22 \%$ 、 $47.03 \% 、 55.1 \%$. The larger the laser spot diameter is, the better the surface smoothness is.On the basis of foregoing study, it provides guidance for the selection of process parameters in micro laser shock forming, surface quality control and complex shape features of multi-point micro laser shock forming.

\section{Acknowledgements}

The authors are grateful for the support provided by National Natural Science Fund for Youth (NO.51405207), Nature Science Foundation of Jiangsu Province for Youth (NO.BK20140510), China Postdoctoral Science Foundation (NO.2014M561573), Postdoctoral Science Foundation of Jiangsu Province (NO.1301012B), The practice innovation project of the professional degree graduate students in Jiangsu Province (SJLX16_0454) 


\section{References}

[1] Lu Jinzhong,Luo Kaiyu,Feng Aixin,et al.Micro-structural enhancement mechanism of LY2 Aluminum alloy by means of a single laser shock processing [J]. Chinese J. Lasers, 2010, 37(10): 2662 2666.In Chinese.

[2]WANG X, QIU T B, GU Y X, et al. Micro-forning properties of Ti foil under laser indirect shock[J]. Optics and Precision Engineering, 2015,03:632-638.In Chinese.

[3]ZHOU J Z, HUANG L, HUANG S et al. Formability of laser shock-induced high speed flyers[J]. Optics and Precision Engineering, 2014,07:1743-1750.In Chinese.

[4] SHENG J, ZHOU J Z, HUANG S. Characterization and tribological properties of micro-dent arrays produced by laser peening on $\mathrm{ZCuSn10P1}$ alloy[J]. International Journal of Advanced Manufacturing Technology, 2015, 76:1285-1295

[5] A. Salimianrizi, E. Foroozmehr, M. Badrossamay, H. Farrokhpour. Effect of Laser Shock Peening on surface properties and residual stress of Al6061-T6[J]. Optics and Lasers in Engineering, 2015, 77(2): 112-117

[6] Fairland B.P, Wilcox B.A, Gallagher et a1. Laser shock induced microstructural and mechanical property changes in 7075 aluminum[J]. Appl. Phys, 1972,43:3893-3895

[7] Zhou Jianzhong,Zhang Yongkang,Zhou Ming.Study on laser shock forming of sheet meta[J]. Applied laser, 2002, Vol.22(2):165 168.In Chinese.

[8] Abul Fazal,Arif M.Numerical prediction of plastic deformation and residual stress induced by laser shock processing.Journal of Materials Processing Technology,2003,136(2):120-138

[9] FENG X, LI X X, WANG L et al. Fabrication of Micro-dimple Texturing on Gray Cast Iron Surface by Nanosecond Laser[J]. APPLIED LASER, 2015,06:689-692.In Chinese.

[10] WANG X, ZHANG D, GU C X et al. Large area micro bending method by soft punch under laser shock wave based on multi-groove mold[J]. Optics and Precision Engineering, 2014,09:2292-2298. In Chinese.

[11] QIAO H C, ZHAO J B, LU Y. Current Status of Laser- induced Shock Wave Application Technology[J]. Surface Technology, 2016, 45(01):1-6+48.In Chinese. 